\title{
Editorial: Prevention and intervention science: Contributions to developmental theory
}

\author{
DANTE CICCHETTI $^{a}$ AND STEPHEN P. HINSHAW ${ }^{b}$ \\ ${ }^{a}$ Mt. Hope Family Center, University of Rochester; and ${ }^{b}$ University of California, Berkeley
}

In a chapter on the historical roots of the discipline of developmental psychopathology, Cicchetti (1990) predicted that this thenemerging field would, among other integrative functions, help to bridge the gap between basic and applied research and between theoretical and clinical efforts for children, adolescents, and adults (see also Cicchetti \& Toth, 1991, 1992, 1998). Despite this hopeful assertion, in the dozen years since its appearance, there has not been a complete closing of the gap (which, at worst, can resemble a chasm).

In a related vein, the Institute of Medicine (IOM; 1994) report, Reducing Risks for Mental Disorders: Frontiers for Preventive Intervention Research, stated that the field of prevention science could be moved forward through appropriate theoretical integration. The IOM (1994) committee on the prevention of mental disorders presented four integrative core sciences as illustrations of how each had contributed (and would continue to contrib-

Work on this Special Issue was supported, in part, by grants from the National Institute of Mental Health (MH45027 and MH54643) and the Spunk Fund, Inc., to Dante Cicchetti and by grants from the National Institute of Mental Health (U01 MH50461 and R01 MH 45064) to Stephen P. Hinshaw.

Address correspondence and reprint requests to: Dante Cicchetti, Ph.D., Shirley Cox Kearns Professor of Psychology, Psychiatry, and Pediatrics, and Director, Mt. Hope Family Center, University of Rochester, 187 Edinburgh Street, Rochester, NY 14608 or Stephen P. Hinshaw, Ph.D., Professor of Psychology, Tolman Hall \#1650, University of California, Berkeley, CA 947201650. ute) to preventive intervention research. Neuroscience, genetics, and epidemiology comprised three of the sciences. The fourth scientific tradition chosen as a core science was developmental psychopathology.

A central objective of this Special Issue is to document the promise of a developmental psychopathology perspective holds for providing integration and bridging between developmental theory and prevention and intervention and to provide key exemplars of both what has been done and what can be done to achieve this goal. As highlighted below and as is evident in the contributions herein, theory and research on basic developmental processes can and should inform prevention and intervention efforts to a greater extent than is the current norm, and clinical research on treatment and preventive strategies can provide unprecedented and essential insights translatable to the making of further theoretical advances (Hinshaw, 2002a, 2002b; Kellam \& Rebok, 1992; Koretz, 1991).

For example, if the developmental course is altered as a result of the implementation of preventive interventions and the risk for negative outcomes is reduced, then prevention research has contributed to specifying the processes that are involved in the emergence of maladaptive developmental outcomes and psychopathology (Cicchetti \& Rogosch, 1999; Coie, Watt, West, Hawkins, Asarnow, Markman, Ramey, Shure, \& Long, 1993; Kellam \& Rebok, 1992). Accordingly, preventive intervention research can be conceptualized as true 
experiments in modifying the course of development, thereby providing insight into the etiology and pathogenesis of disordered outcomes (Kellam \& Rebok, 1992). Prevention research is based on theoretical models of how risk conditions are related to adverse outcomes, positing processes that link the risk condition to the negative outcome (Institute of Medicine, 1994; Munoz, Mrazek, \& Haggerty, 1996; Reiss \& Price, 1996). Knowledge of developmental norms, appreciation of how developmental level may vary within the same age group, sensitivity to the changing meaning that problems and disorders have at different developmental levels, attention to the effects of developmental transitions and reorganizations, and understanding of the factors that are essential features to incorporate into the design and implementation of preventive interventions all may serve to enhance the potential for optimal intervention efficacy (Cicchetti \& Rogosch, 1999; Cicchetti \& Toth, 1999; Coie et al., 1993; Institute of Medicine, 1994; Munoz et al., 1996; Noam, 1992; Reiss \& Price, 1996; Toth \& Cicchetti, 1999).

Inquiries regarding developmental theory and findings on basic developmental processes are all too often quite removed from both clinical practice and clinical research (Cicchetti \& Toth, 1998; Kazdin, 1999). Despite rhetoric directed to the principle that developmental theory should inform active clinical intervention with children and adolescents - and the converse contention that treatment research should inform relevant theory-the gap between these two endeavors is still broad. Indeed, in many ways those who perform basic developmental research and promote developmental theory appear to constitute a different "culture" from those who pursue related prevention and intervention efforts. At the extremes, clinically oriented investigators and practitioners perceive "basic" academic developmental science as overly concerned with central tendencies and universal, developmental norms, to the exclusion of the rich variability and nonnormative behavior patterns that they confront on a daily basis. Conversely, theorists and academic scientists appear to construe much of the clinical endeavor as atheoretical, practical, and ungrounded in core scientific principles and theories (Cicchetti \& Toth, 1998).

This state of affairs is particularly distressing given (a) the advances that are being made in a host of basic behavioral and biomedical sciences and (b) the urgent clinical needs of large numbers of children, adolescents, and families afflicted by mental and developmental disorders (U.S. Department of Health and Human Services, 1999). Because of the field's still nascent ideas as to the underlying mechanisms of most forms of psychopathology, the need for direct application of basic research advances toward the enhancement of clinical efforts can only be described as essential. Yet, despite the increasing call for "translational" research that can bridge basic and applied efforts, the barriers that exist regarding the application of such basic research advances to clinically relevant work are real (Institute of Medicine, 2000). It is essential that so-called basic investigators receive greater exposure to training in clinical realities and that clinical investigators receive updated information about fundamental processes that are relevant to clinical disorders.

Another means of reducing the schisms that exist between academic researchers and clinicians is to undertake interdisciplinary, collaborative preventive interventions that take into account multiple levels of influence, spanning genes to neighborhoods and individuals to social groups (Cicchetti \& Dawson, 2002). Indeed, these integrative, multidisciplinary efforts that bridge these different cultures can capitalize on unprecedented opportunities for fostering a mutual perspective. A central tenet of developmental psychopathology is that the understanding of atypical development can inform the understanding of normal development, and vice versa, as long as consideration is given to contextual variables and developmental principles in the explanation of how development can go awry (Cicchetti \& Cohen, 1995a, 1995b). We extend this assertion through our contention that methodologically rigorous prevention and intervention science can provide a unique lens through which the processes responsible for the development, maintenance, and alteration of both typical 
and atypical functional patterns can be discerned (Cicchetti \& Toth, 1992; Hinshaw, 2002b; Kellam \& Rebok, 1992).

There are several reasons why prevention and intervention efforts can play an essential role in bridging the worlds of research and clinical work and in fostering theoretical advances. First, investigations of clinical populations may inform understanding of processes responsible for healthy and atypical development, but again, only so long as careful attention is directed to the underlying mechanisms responsible for pathological outcomes (Hinshaw, 2002b). Second, and crucially, whereas much of the work in the field is, of necessity, naturalistic and correlational in nature, given ethical constraints on randomly assigning developing persons to key environmental or psychobiological "conditions," the gold standard for clinical intervention and prevention research is the randomized clinical trial. The experimental nature of such investigations provides an unprecedented opportunity to make causal inferences in the field (Cook \& Campbell, 1979; Kraemer, Wilson, Fairburn, \& Agras, in press). Although the types of independent variables manipulated in clinical or prevention trials may be several steps removed from crucial, underlying etiologic factors, given that such trials are primarily concerned with the practical, clinical goals of alleviating suffering and promoting competence rather than isolating primary causal variables, careful research design and assiduous measurement of ancillary, process variables through which intervention effects may occur can shed unexpected light on theory-driven mechanisms underlying healthy and pathological development (Hinshaw, 2002a; Kraemer et al., in press).

Now that we have argued for the criticality of incorporating developmental theory into the design and evaluation of prevention and intervention trials, one might ask what is meant by developmental theory (and, implicitly, clinical theory) in the title of this Special Issue? At one end of the continuum are grand, inclusive "theories" such as psychoanalytic theory, family systems theory, and learning theory, which implicitly or explicitly guide many therapeutic efforts. Kazdin (1999) contends that these should be termed "approaches" rather than theories per se, given their broad, often untestable nature. At the other end, microtheories include specific networks of assertions of causal relations among key variables, some of which may pertain to the development of psychopathological symptoms or impairments and some of which are focused more specifically on mechanisms of therapeutic change. Coercion theory (related to parent-child interactions in externalizing youth; Patterson, Reid, \& Dishion, 1992), attachment theory (related to parent-infant dyadic relationships; Cicchetti, Rogosch, \& Toth, 2000; Cicchetti, Toth, \& Rogosch, 1999; Lieberman, Weston, \& Pawl, 1991), and cognitive theory (e.g., of internalizing disorders in children, which focuses on cognitive distortions and cognitive deficiencies; Kendall, 2000) are just three of many examples of the types of theoretical models that can be tested, modified, and further developed through intervention research. Dishion and Patterson (1999) present an exemplary account of the mutual interplay of theory testing, model building, and intervention research related to the etiology and maintenance of antisocial behavior patterns.

Furthermore, we note that fundamental tenets of prevention science (Coie et al., 1993; Institute of Medicine, 1994; Koretz, 1991; Reiss \& Price, 1996) include the points that (a) careful scientific review of risk and protective factors for a given condition or impairment must be undertaken before the prevention trial is designed and (b) the trial should measure not only proximal and distal outcomes related to diminution or elimination of psychopathology and promotion of competence but also explanatory, process variables (mediators) that can explain the outcomes. Thus, even more than intervention research, prevention research has explicitly embraced a theoretical stance for the development and evaluation of key preventive efforts. Extending the seminal work of Baron and Kenny (1986), Kraemer, Stice, Kazdin, Offord, and Kupfer (2001) and Kraemer et al. (in press) provide extensive coverage of the concepts of moderator and mediator variables as explanatory factors in the design and execution of both field studies and prevention or interven- 
tion trials. Overall, because prevention trials tend to occur earlier in development than most intervention trials and because they tend to be concerned with key risk factors for the development of psychopathology, they are particularly relevant to the informing of developmental theory.

Another tenet of the discipline of developmental psychopathology is that it is important to understand pathways to competent adaptation, despite exposure to conditions of adversity, and to comprehend the functioning of individuals who, after having diverged onto deviant developmental pathways, resume more positive functioning and achieve adequate adaptation (Cicchetti \& Toth, 1991, 1998; Toth \& Cicchetti, 1999). As research on the contributors to resilient functioning has evolved, several scientists have suggested appropriate directions, based on knowledge of the extant empirical literature, for how to develop preventive interventions aimed at promoting competent adaptation in a variety of high-risk groups (see, e.g., Cowen, 1991, 1994; Luthar \& Cicchetti, 2000; Yoshikawa, 1994). A number of recommendations for competencepromoting interventions have been made, in-

\section{References}

Baron, R. M., \& Kenny, D. A. (1986). The moderatormediator variable distinction in social psychological research: Conceptual, strategic, and statistical considerations. Journal of Personality and Social Psychology, 51, 1173-1182.

Cicchetti, D. (1990). A historical perspective on the discipline of developmental psychopathology. In J. Rolf, A. Masten, D. Cicchetti, K. Nuechterlein, \& S. Weintraub (Eds.), Risk and Protective Factors in the Development of Psychopathology (pp. 2-28) New York: Cambridge University Press.

Cicchetti, D., \& Cohen, D. (Eds.). (1995a). Developmental psychopathology: Vol. 1. Theory and method. New York: Wiley.

Cicchetti, D., \& Cohen, D. (Eds.). (1995b). Developmental psychopathology: Vol. 2. Risk, disorder, and adaptation. New York: Wiley.

Cicchetti, D., \& Dawson, G. (Eds.). (2002). Multiple levels of analysis [Special Issue]. Development and Psychopathology, 14, 417-420.

Cicchetti, D., \& Rogosch, F. A. (1999). Conceptual and methodological issues in developmental psychopathology research. In P. C. Kendall, J. N. Butcher, \& G. N. Holmbeck (Eds.), Handbook of research methods in clinical psychology (pp. 433-465). New York: Wiley.

Cicchetti, D., Rogosch, F. A., \& Toth, S. L. (2000). The cluding (a) they must be firmly grounded in theory and research; (b) efforts should be directed not only toward reducing maladaptation and psychopathology but also at promoting competence; (c) programs must capitalize on the particular resources and strengths of individual children or specific populations; (d) there should be a focus on vulnerability and protective processes that operate across multiple levels of influence; and (e) they should be undergirded by a strong developmental-contextual theoretical perspective (see Luthar \& Cicchetti, 2000, for an elaboration of these guiding principles). To this we add that prevention and intervention efforts should be designed to elucidate the mediators and moderators of resilient outcome and recovery of adaptive function.

In closing, it is our hope that this Special Issue of Development and Psychopathology on the contributions that prevention and intervention science can make to developmental theory will foster collaborations between basic and applied researchers. Such endeavors will enhance both extant developmental theory and the provision of more efficacious and effective services to populations in need.

efficacy of toddler-parent psychotherapy for fostering cognitive development in offspring of depressed mothers. Journal of Abnormal Child Psychology, 28, 135-148.

Cicchetti, D., \& Toth, S. L. (1991). The making of a developmental psychopathologist. In J. Cantor, C. Spiker, \& L. Lipsitt (Eds.), Child behavior and development: Training for diversity (pp. 34-72). Norwood, NJ: Ablex.

Cicchetti, D., \& Toth, S. L. (1992). Editorial: The role of developmental theory in prevention and intervention. Development and Psychopathology, 4, 489-493.

Cicchetti, D., \& Toth, S. L. (1998). Perspectives on research and practice in developmental psychopathology. In W. Damon (Series Ed.), Handbook of child psychology (Vol. 4, 5th ed., pp. 479-583). New York: Wiley.

Cicchetti, D., \& Toth, S. L. (Eds.). (1999). Rochester Symposium on Developmental Psychopathology; Vol. 9. Developmental approaches to prevention and intervention. Rochester, NY: University of Rochester Press.

Cicchetti, D., Toth, S. L., \& Rogosch, F. A. (1999). The efficacy of toddler-parent psychotherapy to increase attachment security in offspring of depressed mothers. Attachment and Human Development, 1, 34-66.

Coie, J. D., Watt, N. F., West, S. G., Hawkins, D., Asarnow, J. R., Markman, H. J., Ramey, S. L., Shure, 
M. B., \& Long, B. (1993). The science of prevention A conceptual framework and some directions for a national research program. American Psychologist, 48, 1013-1022.

Cook, T. D., \& Campbell, D. C. (1979). Quasi-experimentation: Design and analysis issues for field settings. Boston: Houghton Mifflin.

Cowen, E. L. (1991). In pursuit of wellness. American Psychologist, 46, 404-408.

Cowen, E. L. (1994). The enhancement of psychological wellness. American Journal of Community Psychology, 22, 149-179.

Dishion, T. J., \& Patterson, G. R. (1999). Model building in developmental psychopathology: A pragmatic approach to understanding and intervention. Journal of Clinical Child Psychology, 28, 502-512.

Hinshaw, S. P. (2002a). Intervention research, theoretical mechanisms, and causal processes related to externalizing behavior patterns. Development and Psychopathology, 14, 789-818.

Hinshaw, S. P. (2002b). Prevention/intervention trials and developmental theory: Commentary on the Fast Track Special Section. Journal of Abnormal Child Psychology, 30, 53-59.

Institute of Medicine. (1994). Reducing risks for mental disorders: Frontiers for preventive intervention re search. Washington, DC: National Academy Press.

Institute of Medicine. (2000). Bridging disciplines in the brain, behavioral, and clinical sciences. Washington, DC: National Academy Press.

Kazdin, A. E. (1999). Current (lack of) theory in child and adolescent therapy research. Journal of Clinical Child Psychology, 28, 533-543.

Kellam, S. G., \& Rebok, G. W. (1992). Building developmental and etiological theory through epidemiologically based preventive intervention trials. In J. McCord \& R. E. Tremblay (Eds.), Preventing antisocia behavior: Interventions from birth through adolescence (pp. 162-195). New York: Guilford Press.

Kendall, P. C. (Ed.). (2000). Child and adolescent therapy: Cognitive-behavioral procedures (2nd ed.). New York: Guilford Press.
Koretz, D. (1991). Prevention-centered science in mental health. American Journal of Community Psychology, 19, 453-458.

Kraemer, H. C., Stice, E., Kazdin, A. E., Offord, D., \& Kupfer, D. (2001). How do risk factors work together? Mediators, moderators, and independent, overlapping, and proxy risk factors. American Journal of Psychiatry, 158, 848-856.

Kraemer, H. C., Wilson, G. T., Fairburn, C. G., \& Agras, W. S. (in press). Mediators and moderators of treatment effects in randomized clinical trials. Archives of General Psychiatry.

Lieberman, A. F., Weston, D., \& Pawl, J. H. (1991). Preventive intervention and outcome with anxiously attached dyads. Child Development, 62, 199-209.

Luthar, S. S., \& Cicchetti, D. (2000). The construct of resilience: Implications for intervention and social policy. Development and Psychopathology, 12, 857-885.

Munoz, R. F., Mrazek, P. J., \& Haggerty, R. J. (1996). Institute of Medicine report on prevention of mental disorders. American Psychologist, 51, 1116-1122.

Noam, G. G. (1992). Development as the aim of clinical intervention. Development and Psychopathology, 3, 679-696.

Patterson, G. R., Reid, J., \& Dishion, T. (1992). Antisocial boys. Eugene, OR: Castalia.

Reiss, D., \& Price, R. H. (1996). National research agenda for prevention research: The National Institute of Mental Health report. American Psychologist, 51, 1109-1115.

Toth, S. L., \& Cicchetti, D. (1999). Developmental psychopathology and child psychotherapy. In S. Russ \& T. Ollendick (Eds.), Handbook of psychotherapies with children and families (pp. 15-44). New York: Plenum Press.

United States Department of Health and Human Services. (1999). Mental health: A report of the Surgeon General. Rockville, MD: Author.

Yoshikawa, H. (1994). Prevention as cumulative protection: Effects of early family support and education on chronic delinquency and its risks. Psychological Bulletin, 115, 28-54. 